\title{
Globe
}

Revue internationale d'études québécoises

\section{Andrée Rivard, Histoire de l'accouchement dans un Québec moderne, Montréal, Les Éditions du remue-ménage, 2014}

\section{Isabelle Courcy}

Volume 17, numéro 2, 2014

URI : https://id.erudit.org/iderudit/1036247ar

DOI : https://doi.org/10.7202/1036247ar

Aller au sommaire du numéro

Éditeur(s)

Globe, Revue internationale d'études québécoises

ISSN

1481-5869 (imprimé)

1923-8231 (numérique)

Découvrir la revue

Citer ce compte rendu

Courcy, I. (2014). Compte rendu de [Andrée Rivard, Histoire de l'accouchement dans un Québec moderne, Montréal, Les Éditions du remue-ménage, 2014].

Globe, 17(2), 219-221. https://doi.org/10.7202/1036247ar d'utilisation que vous pouvez consulter en ligne.

https://apropos.erudit.org/fr/usagers/politique-dutilisation/ 
prononciations elles-mêmes, la plupart ayant fait l'objet d'études ou de mentions dans des publications spécialisées. Il pourrait même être étonné de ne voir aucune référence à celles-ci.

Gendron suggère que, au début du XIX siècle, l'accent traditionnel était largement partagé par tous les Québécois de statuts sociaux différents. Pourtant, on peut présumer qu'il y avait tout de même des prononciations en concurrence. Par exemple, la concurrence entre les prononciations [wa] et [we] - [we] du graphème $o i$, emblématique de la France du XVIII ${ }^{e}$, qui a créé une polémique entre Maguire et Demers (p. 15), a-t-elle vécu dans la vallée laurentienne? L'auteur n'analyse pas les données linguistiques dans ce cadre. Son choix s'explique sans doute par la difficulté du projet et par la nature même de son corpus, à savoir les remarques des pédagogues qui, de par leurs visées, ne signalaient que les prononciations qui étaient différentes de celles du français parisien moderne.

Luc Ostiguy

Université du Québec à Trois-Rivières

\section{Andrée Rivard \\ Histoire de l'accouchement dans un Québec moderne, Montréal, Les Éditions du remue-ménage, 2014.}

Réfléchir à la médicalisation de la naissance, c'est chercher à comprendre comment la science s'est progressivement emparée de l'une des expériences humaines les plus fondamentales, sans égard au fait que la grande majorité des femmes enceintes soient en santé ou qu'elles aient une grossesse «normale». Ce livre, issu des recherches doctorales de l'auteure, s'inscrit dans le champ des recherches critiques et des réflexions féministes, d'où son postulat de départ voulant que les femmes, actrices de premier plan, soient "porteuses du changement social» (p. 25). Pierre de touche de la thèse mise de l'avant, ce changement concerne l'émergence de nouvelles attentes individuelles quant aux conditions de mise au monde qui se manifestent, à partir des années 1960, "par une affirmation sans précédent des droits des femmes" (p. 129). Sur le plan théorique, l'auteure mobilise les travaux du sociologue Alain Touraine sur la modernité ainsi que la perspective foucaldienne sur le biopolitique pour analyser les rapports que les femmes entretiennent avec les appareils médical et étatique sur l'accouchement, et ce, 
à la lumière des mutations sociales survenues au Québec au courant du dernier siècle.

La première partie du livre porte sur des facteurs ayant concouru à façonner les mentalités et permis la montée de la médicalisation de l'accouchement autour des années 1950. L'idée qui est d'abord développée se révèle dans le titre du premier chapitre: «La médecine obstétricale, icône de la modernité». L'auteure montre comment la médecine, posée en idéal de la modernité, est parvenue à s'infiltrer dans les sphères les plus intimes de la vie des individus en imposant dans les consciences une vision mécaniste du corps qui en appelle à des normes et à des comportements de santé jusqu'alors jamais vus. La promesse d'un accouchement "sans risque» assuré par les progrès de la médecine moderne sera rapidement intériorisée par les Québécoises. Dans le deuxième chapitre, il est question de la "génération lyrique ", les premiers-nés et les premières-nées du baby-boom (Ricard, cité par Rivard, p. 88-91). L'historienne montre comment les aspirations de cette génération de jeunes adultes voulant faire une rupture avec le passé pour «entrer dans une modernité qui semble arriver chez eux [et chez elles] plus tardivement qu'ailleurs» (p. 88) ont favorisé l'amplification et l'intégration des messages modernistes de la vision médicale. En ces "temps nouveaux", l'accouchement moderne est promu comme étant "sans risque " et "sans douleur ", ce qui signifie le plus souvent un accouchement dirigé en milieu hospitalier avec anesthésie générale de la parturiente (p. 129).

La deuxième partie de cet ouvrage, composée des troisième et quatrième chapitres, s'attarde sur le mouvement d'affirmation porté par le désir partagé par plusieurs Québécoises d'accoucher selon les méthodes de «l'accouchement conscient ", c'est-à-dire sans médicaments pouvant altérer leur conscience et en présence de leur conjoint (p. 134). En opposition avec le modèle dominant de l'accouchement dirigé, ces demandes seront généralement très mal accueillies par le corps médical et le personnel hospitalier. Néanmoins, des initiatives originales verront le jour comme le Centre psychoprophylactique d'accouchement sans douleur de Québec (1957-1968), qui fait l'objet du quatrième chapitre. Par la restitution de témoignages et l'analyse d'archives, l'historienne montre comment cet espace a permis à des couples de vivre l'expérience de la mise au monde dans une vision renouvelée de la naissance selon laquelle la participation active de la femme était valorisée, tout comme l'engagement des pères dans le processus d'enfantement et au sein de la famille en général. Ce terrain d'exploration, utile à la poursuite de la thèse soutenue par l'auteure, apporte une contribution importante à l'histoire des femmes ainsi qu'à celle de la pratique infirmière au Québec. 
Suivant le fil d'Ariane qu'est l'affirmation croissante des droits individuels des Québécoises à l'égard de la naissance depuis le dernier siècle, Andrée Rivard s'intéresse par la suite à l'appareil médico-étatique ayant atteint son paroxysme durant la Révolution tranquille et dont les dispositifs ont amené plusieurs actrices (mères, militantes, infirmières, journalistes, etc.) à en dénoncer les abus (p. 30). La situation de dépendance dans laquelle sont placées les femmes à l'égard de la biomédecine fait également l'objet de contestation. De nouvelles propositions seront formulées afin de favoriser une plus grande humanisation des naissances, allant de certaines modifications dans la pratique médicale (dont l'application réelle apparaît mitigée) à l'intégration des sages-femmes dans le réseau de la santé. Par ailleurs, l'analyse de plusieurs documents (ex. mémoires, rapport de recherche, publications de collectifs citoyens, thèse de doctorat) amène l'auteure à conclure que " [s]i les militantes avaient espéré "humaniser la naissance" et redonner le pouvoir aux femmes, le résultat a plutôt été d' "humaniser la médicalisation de la naissance” "(p. 283). Enfin, le dernier chapitre est consacré au récit d'expériences maternelles. Par la présentation de ces témoignages, l'auteure offre des visions incarnées des événements et des faits qu'elle expose dans les chapitres précédents, et ce, tout en prenant précaution de considérer la complexité des vécus, des trajectoires de vie et des différences individuelles des participantes. Soulignons par ailleurs que ces expériences féminines sont celles de femmes francophones et mariées, et ne permettent donc pas de rendre compte du vécu d'autres mères, telles que les mères amérindiennes, celles que l'on a longtemps appelées «les filles-mères», les femmes venues d'ailleurs (autre que de la France) ou encore celles qui ont été psychiatrisées ou criminalisées.

Frôlant les 500 pages, le livre d'Andrée Rivard est une somme qui impressionne par sa richesse et sa rigueur d'analyse. Si l'histoire récente de la naissance au Québec était un territoire très peu exploré jusqu'à ce jour, cet ouvrage y contribue de façon importante. La lecture de ce livre est à la fois passionnante et bouleversante. Elle est également propice à l'émergence d'une réflexion sur la peur du risque qui empreigne le social et qui est employée pour "dresser» les corps, en particulier celui des femmes, comme cette analyse de l'accouchement dans un Québec moderne le démontre bien.

Isabelle Courcy

Université d'Ottawa 